\title{
Proposing HRBAIM: (Human Robotics based Animal Interaction Method) by using Haptic Technology
}

\author{
Aina Sharma \\ Department of Computer \\ Science \& Engineering \\ Sri Sai College of Engg and \\ Technology, Manawala \\ (Amritsar) Punjab (India)
}

\author{
Inderpal Singh \\ Department of Computer \\ Science \& Engineering \\ CKD Institute of Management \\ and Technology, Taran Taran
}

\author{
Rimmy Chuchra \\ Department of Computer \\ Science \& Engineering \\ Sri Sai College of Engg and \\ Technology, Manawala \\ (Amritsar) Punjab (India)
}

\begin{abstract}
This paper presents a new animal inspired methodology (AIM) named HRBAIM that is termed as human robotics based animal interaction method. Here, humans and robotics will perform a collaborative task by utilizing haptic technology and takes a joint action in our daily life works. This paper shows a pet dog can be handled or controlled by the machine robotics where robotics acts as a master for pet dog. The instructions are given to pet dog by his master who is robotics and the overall control is in the hand of human who is act as a Grand Master and robotics act as a slave for grand master (who is human). For providing continues surrounding interactions authors utilizes haptic technology. This collaboration/mutual-co-ordination of AIM (Animal Inspired Method) plays a vital role in daily life like during the absence of humans in their homes robotics will take care of their pet dogs. The other benefit to utilize this animal inspired methodology is to reduce the human burden, save energy, save time and most importantly transferring human responsibilities to the Robotics machines that ultimately provides a regular contact of humans with their pet dogs even in their absence. Hence, robotics easily handle problems occurs with pet dog artificially with a step closer to natural touch. In addition, this proposed methodology may also help to learn animals behavior to humans in intelligent manner..
\end{abstract}

\section{Keywords}

Human-Robotic Interaction, Haptic Technology, Tactile Sensors, Holographic Interactions.

\section{General Terms}

Human, Pet Dog

\section{INTRODUCTION}

As professionals become increasingly busy at work and especially on tours for business purposes on that time their pets are ignored by them. No one is there in their absence for take care of their pet dog. So, researchers developed a new methodology named Haptic technology that enables humans to assure with their pets whose main function is to provide regular or continues environment interactions especially in their absence in home. Haptic technology is an interdisciplinary field [13][27][12] in neuromorphic engineering [46] that provide tactile sensation when human interact with a computer [12]. It provides non-visual form of data communication [10] in which people and animals communicate [38] via touching [16][30][39] and sensing [8][43]. The main objective of haptic technology is a deeper understanding of human perception [7]. In nineteenth century, researchers were uses traditional technologies like codex for reading human perception [7] that did not give efficient results [20] so researchers replaced that old or traditional approach with new concept that is called haptic technology. The main significance to utilize this technology is it provides a deeper understanding between human and robotics through sensation. The machine haptics interaction (that is device interaction) is in the form of computer haptics that include various functions as an example rendering, modeling and stability etc and that can be easily diagrammatically represented as in figure 1:

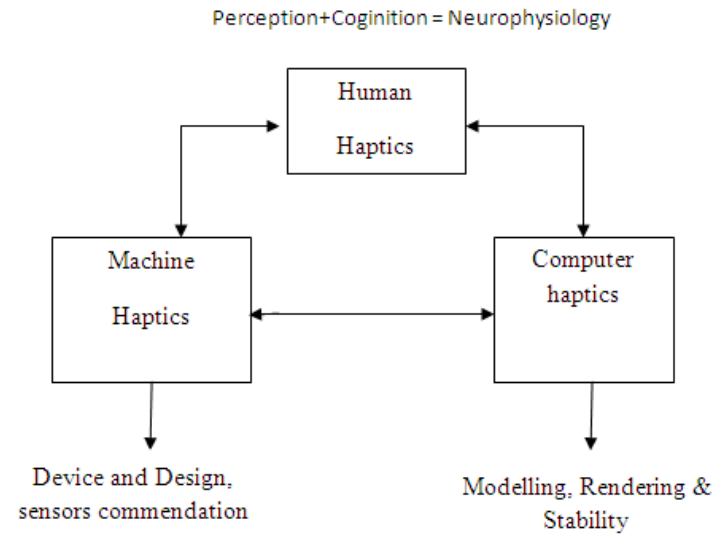

Fig. 1: A roadmap for Human Haptics. [12]

and before performing remote interactions through haptic technology, then at first human operator is designed a haptic interface then linked up with virtual interface that can be diagrammatically represented in figure 2 :

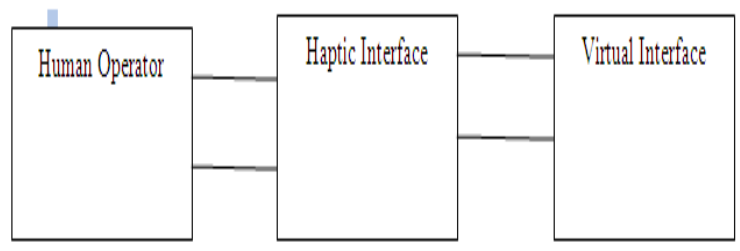

Fig.2: Through Haptic Rendering : The interaaction between human operator and virtual interface[9].

The main function of haptics interface [24] [32] is to solve problems occur during continues environmental interactions with virtual [22][25] objects and real world objects[6][25].

Once human operator is connected with a virtual interface then the live surrounding interactions between both of them will be started that can be easily diagramatically represented in figure 3 : 


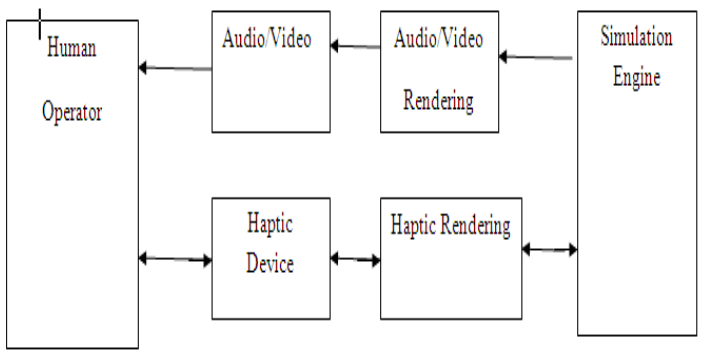

Fig.3 : Internal Working of human operator with haptic device[11][29]

As different types of touch screen technologies [18] viz. resistive touch, capacitive touch, surface acoustic wave (SAW) and optics imaging [14] are used in haptic technology sometimes it can be named as Kinect technology [15]. It mainly uses tactile sensor [47] [48] with haptic feedback device [49]. The reason to use tactile sensor [13][47][48] is it performs its function in well-mannered and provide excellent results without sharing its device feedback [19] with other connected devices. That can be easily explained with the help of practical real life example as like haptic device is attached with cow that give feedback in the form of real feeling of bovine anatomy[37]. As researchers collected more efficient results after usage of this technology they clubbed or merged haptic technology in several different fields which are used in our real life as an example in medical field surgeons[36] used this technology too much [18]. The reason to prefer more this technology is to improve the accuracy of remote interactions [23] especially when deal with their patients and even through virtual assistants who are robotics [17][31][35] in hospitals, industry or house hold robotics. For providing remote interactions through virtual assistants robotics developers designed a mechanism for controlling their arms that can be easily diagrammatically represented as in figure 4 :

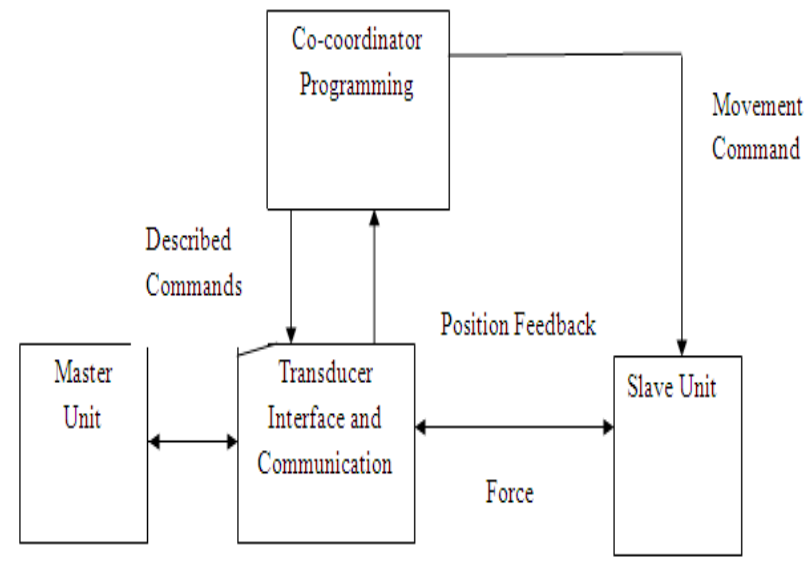

Fig.4: Designed Mechansim for Controlling of Robotics Arm[32].

In general, Robotics body is built up of artificial skin that sometimes also called "ESKIN" (electronic Skin)[41][42][44] that helps to sense environment[34] in a better way due to its stretchable nature that remains sensitive to pressure and temperature[45][50] and results in the form of haptic intelligence that ultimately improve haptic device decision making ability [26][33].
In this paper authors are proposing a new animal inspired methodology [40] named "HRABI" that is termed as human robotics based animal interaction. Humans and robotics performs a collaborative task for taking joint action having master-slave relationship. The pet dog is controlled or handled by his master robotics during absence of their grand master (who is human) in their homes. The working on this new designed methodology majorly depend on grand master instructions. This collaboration or mutual-co-ordination of AIM plays a vital role in our daily life now a days like during the absence of humans in their homes virtual assistants (robotics) will take care of their pet dog. The other benefits to utilize this animal inspired methodology is to reduce the human burden, save energy, save time, shifted human responsibilities to virtual assistants (who are robotics) manual interactions [12] that helps to enhance the level of learning [21] as an example PHANTOM (personalized learning with haptics when teaching with online media) Project that is divided in several parts and can be diagrammatically represented as in shown in figure.5:

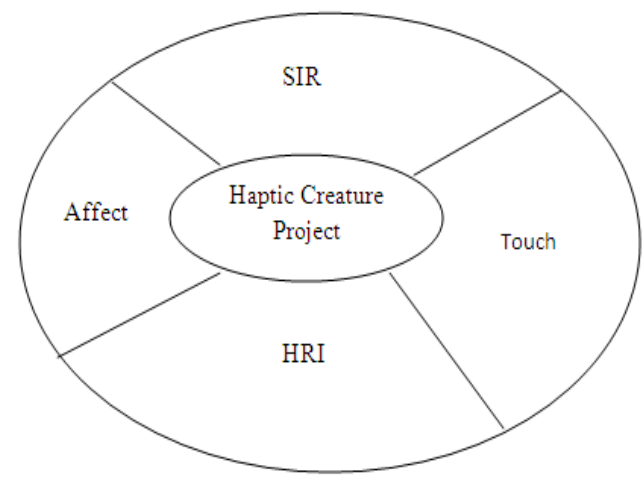

Fig.5: Devidation of Haptic Project[38].

Where HRI: Human Robotics Interaction.

SIR: Socially Interactive Robotics.

whose purpose is to control the device that respond to a person who touch and helps to manipulate haptics that further linked to graphical computer simulated displays which provide feedback to the learners [28] and most significant use is it actually transfers human responsibilities to the Robotics machines and ultimately it will provide a regular contact of humans with their pet even in their absence. Hence, this new designed methodology helps to humans for learning animal behavior in natural but intelligent way.

\section{RELATED WORK}

(Rimmy Chuchra \& Ramandeep Kaur et al Feb-2013) This paper discussed about the joint action taken by the humans and robotics for performing any task. Humans and robotics holds master/slave relationship where interface is act as a sandwich between the humans and robotics. The use of interface is to provide communication between human and robotics in natural way where human acts as a master and is responsible for giving instructions to robotics and robotics always acts as a slave that work as per instructions given by their master. The communication flow methodology between human and robotics can be shown in fig.6: [2] 


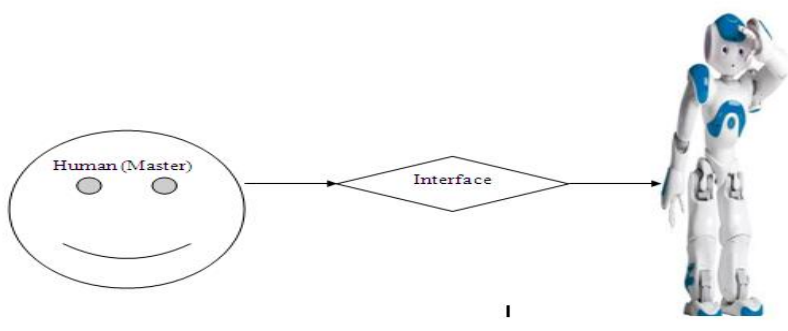

Fig.6: HRI: Shows Master/Slave Relationship.

(Rimmy Chuchra \& R.K Seth et al May-June 2014): Authors had been proposed a new procedure termed as "Humanrobotics Interaction based analysis-Using data mining techniques" that shows how humans and robotics performed any task collectively by utilizing three different data mining techniques viz. classification, regression analysis and time series analysis. This designed methodology worked only with single type of data input format. It must be in discontinuous form (i.e. - in digital form). Theoretical and experimental based analysis investigated in this paper with significant results. [1]

(R.K Seth \& Rimmy Chuchra et al Jan 2015): Authors had designed a new communication flow methodology that works on two separate types of inputs given by the user viz. analog and digital form. The designed methodology also provides more natural way of communication while utilizing interface. Instructions can be easily managed by robotics given by the master-human. [3]

(Rimmy Chuchra \& R.K Seth et al April 2016): This paper presents the synergetic interaction between man and machine having master-slave relationship where a man act as a master and nano-robot act as slave. Here, nano-robot uses sixth sense technology device for mind mapping of idea by utilizing blue brain with swarm intelligence. The major benefit to use sixth sense technology device by nano-robot is to provide protection of human body from the radiations emitted by it (SSTD- as an example smart phone). The collaboration between man and machine intelligence leads to achieve a smart or intelligent joint action for developing projects in any industry or daily life works. [4]

(Rimmy Chuchra \& R.K Seth et al December 2015): This paper presents a qualitative approach for the improvement of existing education system that is termed as "Faculty Performance Metric Scale" (FPMS) by utilizing the application of ambient intelligence. Its major goal is to improve the overall quality of any education system by utilizing "FPMS". Authors uses a methodology that shows mutual interaction among humans and service robotics having master slave relationship where human act as a master and service robotics act as a slave. The main function of service robotics is to store and monitor the faculty members during delivery of lectures. The collaboration between human and service robotics leads to achieve a joint action and shows active team work participation by utilizing natural interactions. In this way, this proposed approach provides a more natural way of communication among humans and service robotics. [5]

\section{RESEARCH DESIGN}

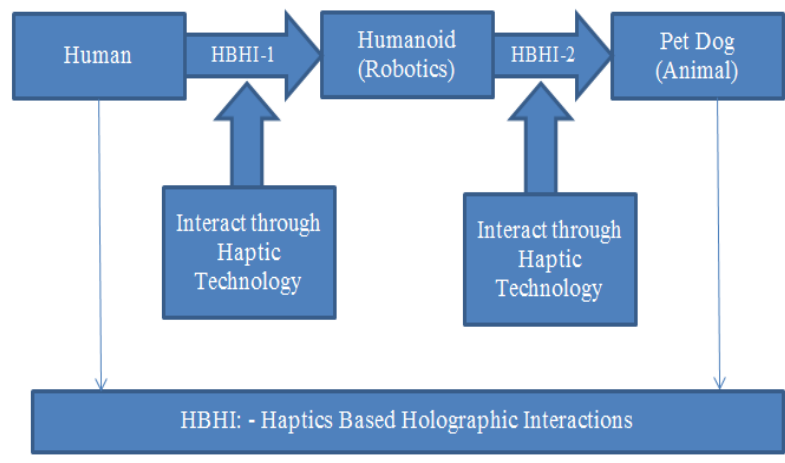

Fig. 7: A Roadmap for Animal Inspired Methodology for improving the interactions with the environment:

\section{WORKING}

At first step, an instruction in the form of command is given by his grand master who is human to the slave who is virtual assistant (robotics) through sensation of touch of human (who is his grand master) robotics is unlocked via haptic technology. The complete functioning of commands is based on the programming logic implemented in robotics arm as shown in above figure 4 . In the second step, once robotics will be unlocked, through tactile sensors robotics will easily interact with the pet dog with a simple natural touch. The main benefit to utilize tactile sensors in pet dog body is to detect the vibrations in pet dog body in any situation as an example pet is feeling well, feeling irritated, mood for wandering, not feeling well etc. A simple touch provides a medium for social interactions between human and animal through virtual assistant (robotics machine). And the other major benefit is human can easily learn animal behavior by utilizing haptic technology via holographic interactions. Hence, this proposed animal inspired methodology (PAIM) helps us to provide a strong remote interactions or sound remote interactions. In other words, you may say something like out of science fiction.

\section{CONCLUSION}

This paper discussed about how haptic technology plays a significant or vital role in our daily life work and also proposed a new animal inspired methodology named HRBAIM (Human Robotics Based Animal Interaction Method) for providing continues remote interactions of humans with surrounding say with the environment (i.e. Interactions with real world objects). Here, Authors contributed their efforts for providing an improved version of interaction of humans with the animals by utilizing haptic technology. The complete working of this new designed animal inspired methodology is based on master-slave relationship. The most important thing is the real world object says pet dog is controlled or handled by virtual assistant machines (say robotics) that ultimately help to reduce human burden while transferring their responsibilities to machines when they are far away from their homes and provide a regular contact of humans with their pets even in their busy schedule. Hence, this HRBAIM provide a more natural touch of interaction between human and animals through machines in the form of non-verbal communication. Hence, by utilizing this haptic technology users will regularly contact with their pets even in their absence in smart and intelligent manner. 


\section{REFERENCES}

[1] Rimmy Chuchra \& R.K Seth March 2014. Human robotics interaction based analysis-Using DMT, International Journal of Computer Science and Information Technology.

[2] Rimmy chuchra \& Ramandeep kaur, Feb 2013. Human robotics interaction with data mining techniques, International Journal of Emerging Technology and Advance Engg.

[3] R.K Seth \& Rimmy Chuchra, January 2015. Synergetic Interaction among Humans and Robotics by Proposing Communication Flow Methodology, International Journal of Computer Applications.

[4] Rimmy Chuchra \& R.K Seth, April 2016. Collaborative use of Sixth Sense Device, Blue Brain and Swarm Intelligence for Performing Joint Actions, International Journal of Computer Applications.

[5] Rimmy Chuchra \& R.K Seth, December 2015. Proposing Faculty Performance Monitoring Scale (FPMS) as an Application of Ambient Intelligence, International Journal of Computer Applications.

[6] Stale Stenslie, Tony Olsson, Andres Goransoon and David Cuentielles, 2012. Mobile Haptic Technology Development through Artistic Exploration, Springer.

[7] Emanuele Ruffaldi and Massimo Bergamo, Haptic Interfaces for embodiment in virtual Environment, PERCRO Lab, Itlay.

[8] Sorabh Gupta,Swati Uppal \& Nisha Sharma, 2011.Technology Based on Touch: Haptic Technology, International journal of computational engg. \& management.

[9] Haptic Technology in surgical simulation \&mechanical training a touch revolution, 2011.IEEE.

[10] Sabrina Panels, Where are we with Haptic Visualization, Computing Lab, UK.

[11] Francois Conti, Federico Barbell \& Kenneth Salibury, Haptic Rendering: Introductory Concepts, Standford Robotics Lab, USA.

[12] Prof. Amit.M Sahu, Miss Snehal.N Meshram, April 2014.Haptic Science \& Technology in surgical simulation, Medical Training \& Military Applications, International journal of computer science \& mobile computing.

[13] B.Divya Jyothi and R.V Krishaiah,September 2013.Haptic Technology- A Sense of Touch,International Journal of Science and Research,Hyderabad.

[14] www.sensorsmag.com/sensors-products/touch-sensorsnews/haptic-touchscreen-technology-market-see-41cagr-2013-15367.

[15] Emil Petrin, EIsaddik, Juan Silva \& Mauricio orozeo, Role of haptics in games, University of Ottawa, Canada.

[16] Anilesh A.Alkari, Mohit V.Shivramwar \& Vaibhav N.Fulkar2010.Applications of haptics Technology in advance Robotics, IEEE.

[17] Rakesh U.Veri,Prof R.K Moje \& Akshay S.Tote, March 2013. Haptic hand for heavy duty works in industries,
International Journal of innovative research in electrical, electronics, instrumentation \& control engg.

[18] Dr. D.S Chaudhari, P.L Paikrao \& V.R Vaidya, May 2013. Intelligent virtual touch screen showing finger movement, International journal of engg. Science \& innovative technology.

[19] Susan Todd \& Dr. Shamus P.Smith 2008. Usability Evaluation of a haptic based clinical skills training system, International Journal of clinical skills, UK.

[20] Anne Mangen, 2008. Hypertext fiction reading: Haptics \& Immersion, Journal of research in reading,D.O.I:$10.1111 / \mathrm{J} .1467-9817$

[21] Kian Meng Yap \& Chit Su mon, An investigation into virtual object's learning by using haptic interface for visually impaired children, Sunway Academics Journal.

[22] Suzraim a Shoon So \& Irraivan Elam Varuthi, Noor Hazrin Hani M Hanif, December 2009. Simulation \& Control of sensory mode interaction, International journal of engg \& technology.

[23] Saeid nahavandi.Timothy Black, James Mullins \& Christopher Mawson, Haptic control of multi-axis robotics system, Intelligent system research lab, Australia.

[24] Ashok G.Bhandange, Shrikant R.Padloe, Sandip S.Mane,S.S Lavhate,2014. Industrial Burr Collecting Robot using Haptic Interface.

[25] Radhika Nimje, Laxmi Dubay,Shilpa Khorkate \& Shruti Joshi, January 2015. Haptic gloves controlled robotics arm using MEMS accelerometer, International journal of innovations in engg. Research and technology.

[26] Subhajeet Laga, March 2013. Recent Trendz in haptic technology: - A Simplified Efficient approach, International journal of emerging trendz in electrical and electronics.

[27] Abdulmotaleb EI Saddik,Mauricio Orozeo,2007.A guided Tour in haptic audio visual Environment and applications", International journal of advanced media and communication.

[28] Developing \& researching personalized learning with haptics when teaching with online media (PHANTOM) Methodological strategies and solutions for technological, curriculum \& teaching challenges, Proposal for a symposium at WCCE 2009 Conference, 2008.

[29] Chinmay S.Deshpande, May 2015. The Study of haptics in medical training simulation, International journal of advanced research in computer engg and technology.

[30] V.N Fulkar, 2010.Applications of haptics technology in advance robotics, IEEE.

[31] [31]Prof. A.Reshamwala, April 2015.A Review on Robot Arm using Haptic Technology, International journal of advanced research in electrical electronics and instrumentation engg.

[32] Abdelfatah M.Mohamad \& A.B Shark awy, July 2014.Haptic control development of robotic arm", International journal of automation and systems.

[33] ]Kumar Rahul Dev, Asha Bagoshara \& Dimple Saproo, November 2013. Haptics: - Technology based on touch, 
International journal of scientific research engg. \& technology.

[34] Sudipto Mukhrjee \& Aisranou Oshawa Rait, Teleperation with haptics.

[35] Gerhard K.Kraetzschmar \& Rhama Dwiputra, September 2014. Haptic interface for domestic service robot, Journal of automation and control engg.

[36] R.Rajan, Haptics Technology in surgical simulation \& medical training, U.G Scolar, Villumpuram.

[37] www.betsoline.com/news/latest-headlines/hapticanimals-being-sold-to-international-net-schools.html.

[38] Karon E. Macl Can \& steve Yohana, the haptic creature project: Social HR Interaction through Affective touch: SPIN (Sensory Perception \& Interaction Research Group), Canada.

[39] Mr Emmanuel Hans \& Anjali Hans, February 2015. Kinesics, Haptics and Proxemics: Aspects of non-verbal Communication, IOSR Journal of humanities \& social science.

[40] Jorn Hurtienne,Yuki Sakakibara \& Diana Loffeer, August 2015. Insect Behavior as source of inspiration for designing intuitive human computer interaction proceedings, $19^{\text {th }}$ technical congress of the IEA,Melborne.
[41] www.livescience.com/38302-sensor-artificial-skintouch-prosthetics.html.

[42] www.livesciences.com/12954-bionic-humans-artificiallimbs-technologies.html.

[43] cacm.acm.org/magzines/2015/5/186013-robots-with-ahuman-touch/fulltext.

[44] www.huffingtonpost.com/entry/electric-sensors-let-youuse-your-phone-by-touching-your-skin-55c8e $72 \mathrm{de} 4 \mathrm{~b}$.

[45] www.theguardian.com/science/2005/aug/18/robots.

[46] www.economist.com/node/779503.

[47] m/id/13207686/ns/technology-and-sciencescience/t/sensor-could-bring-human-touchrobots/\#.vefitw4rdkg.

[48] physicsworld.com/cws/article/news/2013/app/26/nanowi re-transistor-array-as-touch-sensitive-as-human-skin.

[49] https://www.asme.org/engineeringtopics/articles/robotics/the-sensing-robots.

[50] https://deveentral.k5.com/portals101cache/pdfs/2807/our -five-senses-on-sensors.pdf 